\title{
Assessing Clivia taxonomy using the core DNA barcode regions, matK and rbcLa
}

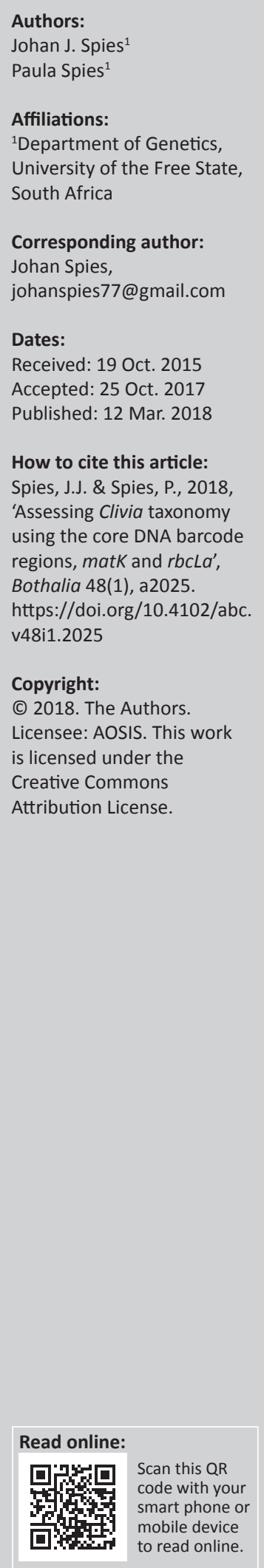

Background: Clivia is a genus of the family Amaryllidaceae endemic to South Africa and Swaziland. Six species and one natural hybrid have been described. Some morphological traits overlap between some species, thus causing taxonomic confusion.

Objectives: The discriminatory power of the core DNA barcodes (matK and rbcLa) was evaluated, and the current taxonomy of Clivia was assessed.

Method: Seventy-four two-locus DNA barcodes from 4 to 18 specimens per species were generated.

Results: The matK region had a higher mean intraspecific variation of 0.21 compared with the 0.02 of $r b c L a$. The two-locus barcodes have an aligned length of 1335 base pairs. Three species, Clivia mirabilis, Clivia nobilis and Clivia caulescens, are monophyletic in the Bayesian Inference (BI) cladogram. The remaining Clivia species (Clivia miniata, Clivia gardenii, Clivia robusta and their affinities) are paraphyletic. Clivia is divided into 17 haplogroups with those of C. mirabilis and $C$. nobilis being unique. Clivia caulescens has three haplotypes. The Clivia species from the north-eastern distribution range of the Eastern Cape and KwaZulu-Natal provinces have 11 haplogroups and no species-specific DNA barcodes. These groups have no correlation with the current taxonomy or geographical distribution.

Conclusions: Only $37.33 \%$ of the species can be correctly identified with the 'best match' option in SpeciesIdentifier. Clivia mirabilis, C. nobilis and C. caulescens have unique DNA barcodes to identify them. Specimens from the Ngome area in KwaZulu-Natal have a unique DNA barcode, separating them from the rest of C. gardenii. A taxonomic revision is suggested.

\section{Introduction}

Clivia Lindl., a shade-loving member of the family Amaryllidaceae J.St.-Hil., is endemic to South Africa and Swaziland and consists of six species, C. mirabilis Rourke, C. nobilis Lindl., C. caulescens R.A. Dyer, C. miniata (Lindl.) Regel, C. gardenii Hook., C. robusta B.G. Murray et al., and a natural hybrid C. ×nimbicola Z.H. Swanevelder et al. Clivia miniata is the only species with trumpet-like flowers, while the other species have pendulous flowers.

Fraud in the Clivia-trade industry (especially in the pot plant industry) occurs because of misidentification of species when investigating vegetative material. Natural variation in the shape and colouring of the leaves are the main contributing factors. Even identification based on the flowers can be problematic because most of the species with pendulous-shaped flowers can be morphologically very similar. Swanevelder and Fisher (2009) attempted to resolve the problem by creating a taxonomic key. However, this key is only helpful when identifying an adult plant in full bloom accompanied by additional information such as the collection site.

Undescribed species may exist, such as the Clivia populations along the Mzamba and Mtentu rivers in the Eastern Cape, the latter sometimes referred to as 'Clivia maxima', although it has not yet been described as a separate species or even as a cultivar (Dixon 2005). This group of plants has either pendulous or trumpet-like flowers, and unlike the majority of species, it forms a stem at the base of the leaves. It is morphologically at the extreme spectrum of C. robusta. When selffertilised in cultivation, it produces up to $10 \%$ albino plants in the progeny (Dixon 2005).

In addition, the natural yellow-coloured variations of C. gardenii and C. robusta found in nature have been split into citrina varieties (Swanevelder et al. 2006; Swanevelder, Van Wyk \& Truter 2005; Watson 1899) based on the split of a yellow C. miniata specimen, C. miniata var. citrina S. Watson and C. miniata var. miniata (Watson 1899). No provision was made for other colour deviations such as peach, pink, blush or red. 
There is a need for a reliable method to identify Clivia species based on any part of the plant. DNA barcoding has been successfully applied in identification of plant species (e.g. Bruni et al. 2015) as well as in re-evaluating taxonomic status and circumscriptions (e.g. Rastegar-Pouyani et al. 2014).

Two DNA barcoding regions have been selected as universal barcodes in plants, namely rbcLa and matK (CBOL Plant Working Group 2009). The rbcLa region is easy to amplify and sequenced over a broad spectrum of taxa (CBOL Plant Working Group 2009), and it has been suggested as a core barcoding region (Hollingsworth et al. 2009). Although matK is not useful in all plants (Lahaye et al. 2008), it is one of the most rapidly evolving coding sections of the plastid genome, and it is considered to be the equivalent of the animal barcode gene, CO1 (Hollingsworth, Graham \& Little 2011).

This study assesses the current Clivia taxonomy and delimitations of the Clivia species with the core DNA barcodes (mat $K$ and $r b c L a$ ). In addition, the efficacy of these barcodes for Clivia identification is evaluated.

\section{Materials and methods}

A total of 110 specimens, representing six Clivia species and some atypical specimens, were obtained from legal collectors around the country.

DNA was extracted using the modified CTAB method of Rogstad (1992). The matK primer sets of Ford et al. (2009) and rbcLa primers of Levin et al. (2003) and Kress and Erickson (2007) were used for PCR amplification and sequencing amplification. DNA sequences were obtained using an Applied Biosystems 3130 Genetic Analyser. Sequence data are stored in the Barcode of Life Data System (BOLD: Ratnasingham \& Hebert 2007) (Table 1).

TABLE 1: The list of material used for the two core DNA barcoding analyses.

\begin{tabular}{|c|c|c|c|c|}
\hline \multirow[t]{2}{*}{ Species } & \multicolumn{2}{|c|}{ GENBANK Identified number } & \multirow[t]{2}{*}{ Voucher number } & \multirow[t]{2}{*}{ Country/province } \\
\hline & $r b c L a$ & matK & & \\
\hline \multirow[t]{4}{*}{ C. mirabilis } & KX038949 & KX038859 & Spies $8947^{*}$ & Western Cape \\
\hline & KX038947 & KX038857 & Spies $8953 *$ & Western Cape \\
\hline & KX038956 & KX038866 & Spies $8955^{*}$ & Western Cape \\
\hline & KX038953 & KX038863 & Spies $8958^{*}$ & Western Cape \\
\hline \multirow[t]{5}{*}{ C. nobilis } & KX038889 & KX038809 & Spies $8932 *$ & Eastern Cape \\
\hline & KX038901 & KX038816 & Spies $8936 *$ & Eastern Cape \\
\hline & KX038946 & KX038856 & Spies $8937 *$ & Eastern Cape \\
\hline & KX038926 & KX038841 & Spies $8940 *$ & Eastern Cape \\
\hline & KX038895 & KX038812 & Spies 8933 & Eastern Cape \\
\hline \multirow[t]{11}{*}{ C. caulescens } & KX038902 & KX038817 & Spies $8417 *$ & Swaziland \\
\hline & KX038908 & KX038823 & Spies $8487 *$ & Mpumalanga \\
\hline & KX038927 & KX038842 & Spies $8488^{*}$ & Mpumalanga \\
\hline & KX038945 & KX038855 & Spies $8494 *$ & Mpumalanga \\
\hline & KX038950 & KX038860 & Spies $8496 *$ & Mpumalanga \\
\hline & KX038918 & KX038834 & Spies $8497 *$ & Mpumalanga \\
\hline & KX038881 & KX038803 & Spies 8498* & Mpumalanga \\
\hline & KX038894 & KX038811 & Spies 8499* & Mpumalanga \\
\hline & KX038952 & KX038862 & Spies $8500 *$ & Mpumalanga \\
\hline & KX038920 & KX038836 & Spies $8501 *$ & Mpumalanga \\
\hline & KX038928 & KX038843 & Spies $8502 *$ & Mpumalanga \\
\hline
\end{tabular}

TABLE 1(Continues...): The list of material used for the two core DNA barcoding analyses.

\begin{tabular}{|c|c|c|c|c|}
\hline \multirow[t]{2}{*}{ Species } & \multicolumn{2}{|c|}{ GENBANK Identified number } & \multirow[t]{2}{*}{ Voucher number } & \multirow[t]{2}{*}{ Country/province } \\
\hline & rbcla & matK & & \\
\hline & KX038931 & KX038846 & Spies $8503 *$ & Mpumalanga \\
\hline & KX038962 & KX038871 & Spies $8504 *$ & Mpumalanga \\
\hline & KX038903 & KX038818 & Spies $8557^{*}$ & Mpumalanga \\
\hline & KX038925 & KX038840 & Spies $8571^{*}$ & Mpumalanga \\
\hline & KX038916 & KX038832 & Spies $8561 *$ & Mpumalanga \\
\hline & KX038909 & KX038824 & Spies $8562 *$ & Swaziland \\
\hline & KX038923 & KX038839 & Spies 8609* & Mpumalanga \\
\hline \multirow[t]{17}{*}{ C. miniata } & KX038887 & KX038807 & Spies $8327^{*}$ & Eastern Cape \\
\hline & KX038882 & KX038804 & Spies 8391* & Eastern Cape \\
\hline & KX038948 & KX038858 & Spies $8394 *$ & KwaZulu-Natal \\
\hline & KX038936 & KX038849 & Spies $8396 *$ & Eastern Cape \\
\hline & KX038934 & KX038848 & Spies $8406 *$ & KwaZulu-Natal \\
\hline & KX038969 & KX038878 & Spies $8408^{*}$ & Eastern Cape \\
\hline & KX038938 & KX038850 & Spies $8410^{*}$ & Eastern Cape \\
\hline & KX038899 & KX038815 & Spies 8419* & Eastern Cape \\
\hline & KX038930 & KX038845 & Spies $8469 *$ & Eastern Cape \\
\hline & KX038964 & KX038873 & Spies $8470 *$ & Eastern Cape \\
\hline & KX038911 & KX038827 & Spies 8558* & Mpumalanga \\
\hline & KX038922 & KX038838 & Spies $8616^{*}$ & KwaZulu-Natal \\
\hline & KX038963 & KX038872 & Spies 8617 & KwaZulu-Natal \\
\hline & KX038905 & KX038820 & Spies $8637 *$ & KwaZulu-Natal \\
\hline & KX038921 & KX038837 & Spies $8667^{*}$ & Eastern Cape \\
\hline & KX038924 & - & Spies 8686 & Eastern Cape \\
\hline & KX038885 & - & Spies 8689 & Eastern Cape \\
\hline C. aff. miniata & KX038921 & KX038837 & Spies 8324 & Unknown \\
\hline \multirow[t]{17}{*}{ C. gardenii } & KX038906 & KX038821 & Spies $8367^{*}$ & KwaZulu-Natal \\
\hline & KX038883 & KX038805 & Spies $8368^{*}$ & KwaZulu-Natal \\
\hline & KX038897 & KX038814 & Spies 8369* & KwaZulu-Natal \\
\hline & KX038965 & KX038874 & Spies $8374 *$ & KwaZulu-Natal \\
\hline & KX038896 & KX038813 & Spies $8376^{*}$ & KwaZulu-Natal \\
\hline & KX038951 & KX038861 & Spies $8403 *$ & KwaZulu-Natal \\
\hline & KX038966 & KX038875 & Spies $8405^{*}$ & KwaZulu-Natal \\
\hline & KX038933 & KX038847 & Spies $8418^{*}$ & KwaZulu-Natal \\
\hline & KX038939 & KX038851 & Spies $8444 *$ & KwaZulu-Natal \\
\hline & KX038961 & KX038870 & Spies $8615^{*}$ & KwaZulu-Natal \\
\hline & KX038972 & KX038880 & Spies $8780 *$ & Eastern Cape \\
\hline & KX038954 & KX038864 & Spies $8884^{*}$ & KwaZulu-Natal \\
\hline & KX038914 & KX038830 & Spies $8885^{*}$ & KwaZulu-Natal \\
\hline & KX038957 & KX038867 & Spies $8887^{*}$ & KwaZulu-Natal \\
\hline & KX038955 & KX038865 & Spies 8888* & KwaZulu-Natal \\
\hline & KX038958 & KX038868 & Spies 8889* & KwaZulu-Natal \\
\hline & KX038915 & KX038831 & Spies 8892* & KwaZulu-Natal \\
\hline \multirow[t]{4}{*}{ C. robusta } & KX038917 & KX038833 & Spies $8415^{*}$ & KwaZulu-Natal \\
\hline & KX038968 & KX038877 & Spies $8440 *$ & KwaZulu-Natal \\
\hline & KX038967 & KX038876 & Spies $8442 *$ & Eastern Cape \\
\hline & KX038940 & KX038852 & Spies 8462* & KwaZulu-Natal \\
\hline
\end{tabular}

Source: Authors' own work

*, matK and/or rbcLa sequences done by CCDB on DNA collected and extracted by authors.

The matK and rbcLa regions were separately analysed using the online tools in BOLD (Ratnasingham \& Hebert 2007) and Geneious R6 software (http://www.geneious. com, Kearse et al. 2012). Sequences were aligned with the aid of Muscle (Edgar 2004). Only sequences with no missing data were analysed. The barcode gaps' (nearest neighbour, NN) intraspecific distances were determined for both regions separately using the Kimura-2-parameter distance model in BOLD Systems (Ratnasingham \& Hebert 2007). 
TABLE 2: The distance summaries of the matK and rbcLa regions of Clivia calculated with Barcode of Life Data System online tools.

\begin{tabular}{|c|c|c|c|c|c|c|c|c|}
\hline Region & Relationship & $n$ & Taxa & Comparisons & Min Dist (\%) & Mean Dist (\%) & Max Dist (\%) & SE Dist (\%) \\
\hline \multirow[t]{2}{*}{ matK } & Within species & 72 & 7 & 459 & 0 & 0.21 & 0.7 & 0 \\
\hline & Within genus & 73 & 1 & 2169 & 0 & 0.46 & 0.9 & 0 \\
\hline \multirow[t]{2}{*}{$r b c L a$} & Within species & 86 & 7 & 732 & 0 & 0.02 & 0.19 & 0 \\
\hline & Within genus & 87 & 1 & 3009 & 0 & 0.25 & 1.19 & 0 \\
\hline
\end{tabular}

Source: Authors' own work

Mean Dist, mean distance; Min Dist, minimum distance; Max Dist, maximum distance; SE Dist, standard error distribution

TABLE 3: A comparison between the 'best match' and 'all species barcode' options in SpeciesIdentifier to determine the correct, ambiguous and incorrect identifications in percentages (\%).

\begin{tabular}{lcc}
\hline Variables & Best match & All species barcode \\
\hline Correct identification (\%) & 37.33 & 12.00 \\
Ambiguous (\%) & 52.00 & 86.66 \\
Incorrect identification (\%) & 10.66 & 1.33 \\
$\begin{array}{l}\text { Sequence without match } \\
\text { closer than 0.34\% }\end{array}$ & 0 & 0 \\
\hline
\end{tabular}

Source: Authors' own work

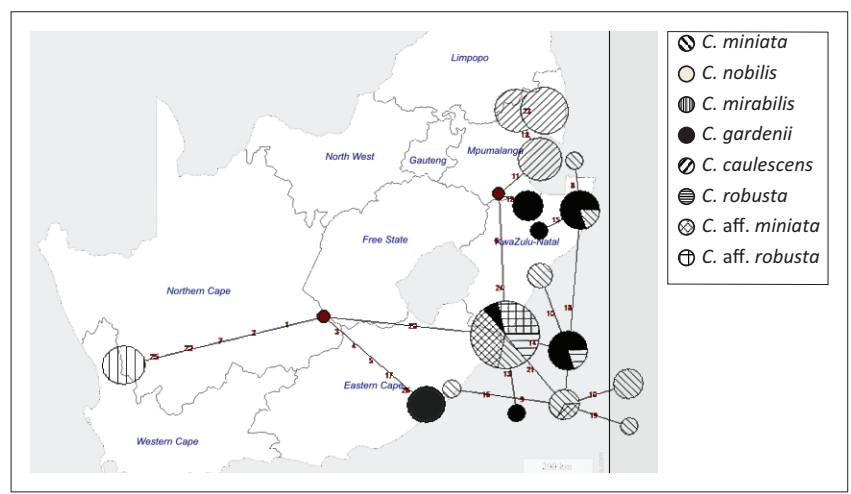

Source: Authors' own work

FIGURE 1: The 17 haplogroups determined with Network 4.6.1.1 and compared with the distribution. The circled haplotypes have no correlation with either geographic distribution or species classification. The values on the branches indicate the number of mutations.

The matK and rbcLa sequences were combined using SequenceMatrix software (Vaidya, Lohman \& Meier 2011). The MrBayes plugin Version 2.0.9 in Geneious R6 was used to construct a Bayesian Inference (BI) cladogram for phylogenetic analysis. The barcoding gap and species partitioning were determined with the online tool Automatic Barcode Gap Discovery (ABGD: Puillandre et al. 2011) with the default settings. A pairwise summary, best match and best close match were determined with the program SpeciesIdentifier (Meier et al. 2006). A threshold value of 0.349 was calculated from the pairwise summary (Meier et al. 2006). A median joining network was constructed in Network 4.6.1.1 to depict the number of mutational steps separating haplotypes of the six Clivia species.

\section{Results and discussion Molecular analyses}

Bidirectional sequences for both matK and rbcLa were obtained for 74 specimens. Only specimens with both gene regions and no missing data were included in this study. The aligned $r b c L a$ region was 552 base pairs and the aligned matK region was 783 base pairs, resulting in a combined aligned length of 1335 base pairs.
The genetic distances of the two core barcoding regions were separately analysed in BOLD (Table 2). The mean intraspecific variation of 0.02 in $r b c L a$ is much lower than the 0.21 in matK. In contrast, the guanine-cytosine (GC) content of rbcLa was higher (mean $43.18 \%$ and range $42.70 \%-45.54 \%$, SE $=0.05$ ) compared to the GC content in matK (mean $29.97 \%$ and range $23.30 \%-32.31 \%$, SE $=0.41$ ). The $r b c L a$ region demonstrated less genetic variation $(1.44 \%$ variable sites) than matK $(2.4 \%$ variable sites).

The ABGD algorithm makes use of pairwise distances to group sequences according to proposed species (Puillandre et al. 2011). Depending on the maximal distance $(P)$ tested $(P=0.00100,0.001668$ or 0.002783$)$, the six species are divided into one to three groups, respectively.

In the pairwise SpeciesIdentifier-based analysis (Table 3), the total overlap is $0.42 \%$ (from $0.0 \%$ to $0.42 \%$, covering $80.03 \%$ of all intra- and interspecific sequences) at a $0.34 \%$ intraspecific cut-off. The majority $(71.61 \%)$ of the intraspecific distances are between $0.0 \%$ and $5.0 \%$ with $28.38 \%$ of the species having an intraspecific distance of $0.0 \%$. The interspecific distances in the genus are mainly $(95.87 \%)$ between $0.0 \%$ and $5.0 \%$. Only a small percentage $(4.12 \%)$ of the species has an interspecific distance equal to $0.0 \%$ and has, therefore, no genetic differences between them.

According to the 'best match' and 'all species barcodes' option in SpeciesIdentifier, correct species identifications are $37.33 \%$ and $12.0 \%$, respectively (Table 3); incorrect Clivia identification can be as high as $10.66 \%$ when using the 'best match' option. The non-variable sites were removed from the sequences, and a network was constructed in Network 4.6.1.1 (Figure 1) with 67 specimens clearly belonging to a species (in other words excluding specimens classified as Clivia 'aff.' specimens) in the data set resulting in 17 haplotypes.

\section{Identification of Clivia species}

Clivia mirabilis is the only species from the Western Cape Province, with several unique characteristics distinguishing it from the other species. Their seeds mature in 4-6 months compared to the 12-24 months of the other species. The root system of $C$. mirabilis is much thicker and more succulent than the other species. Their pedicels turn from red or orange during the flowering stage to green when bearing fruit. Clivia mirabilis is a sought-after plant, and seedlings of other species can be sold to inexperienced buyers under the name of C. mirabilis. 
TABLE 4: The barcoding gap analyses for both the matK and rbcLa gene regions with the mean intraspecific, maximum intraspecific, nearest species and the distance to the nearest neighbour calculated in Barcode of Life Data System online tools for species of Clivia.

\begin{tabular}{lcccc}
\hline Species & $\begin{array}{c}\text { Mean } \\
\text { intraspecific }\end{array}$ & $\begin{array}{c}\text { Max } \\
\text { intraspecific }\end{array}$ & Nearest species & Distance to NN \\
\hline matK & & & & \\
C. caulescens & 0.12 & 0.25 & C. xnimbicola & 0.00 \\
C. gardenii & 0.36 & 0.70 & C. robusta & 0.00 \\
C. miniata & 0.24 & 0.62 & C. robusta & 0.00 \\
C. mirabilis & 0.00 & 0.00 & C. robusta & 0.37 \\
C. xnimbicola & 0.00 & 0.00 & C. caulescens & 0.00 \\
C. nobilis & 0.00 & 0.00 & C. robusta & 0.37 \\
C. robusta & 0.12 & 0.25 & C. miniata & 0.00 \\
rbcLa & & & & \\
C. caulescens & 0.00 & 0.00 & C. xnimbicola & 0.00 \\
C. gardenii & 0.06 & 0.19 & C. robusta & 0.00 \\
C. miniata & 0.01 & 0.19 & C. robusta & 0.00 \\
C. mirabilis & 0.00 & 0.00 & C. gardenii & 0.56 \\
C. xnimbicola & 0.00 & 0.00 & C. caulescens & 0.00 \\
C. nobilis & 0.00 & 0.00 & C. gardenii & 0.56 \\
C. robusta & 0.00 & 0.00 & C. gardenii & 0.00 \\
\hline Source: Auth & & &
\end{tabular}

Source: Authors' own work

$\mathrm{NN}$, nearest neighbour; $\times$, named interspecific hybrid.
The flowers of $C$. nobilis are similar to $C$. mirabilis, but are mainly distinguished by their compact umbel and the pedicels are shorter than in C. mirabilis.

The nearest neighbours and barcoding gaps from BOLD are presented in Table 4. Clivia nobilis and C. mirabilis have distances greater than zero to their NNs. The remaining Clivia species do not have a barcoding gap or any significant genetic distances between them and their closest relatives. Clivia nobilis and C. mirabilis each have a single haplotype and demonstrated no gene flow with any other Clivia species. The haplotype network supports the monophyletic grouping of C. nobilis and C. mirabilis with five mutations separating each of these haplotypes from a common ancestor. Further support for separation is provided by a posterior probability of 1 for C. nobilis and 0.958 for C. mirabilis (Figure 2).

Clivia caulescens is distributed as isolated populations in the northern Limpopo and Mpumalanga provinces. The southern C. caulescens populations on Bearded Man Mountain are sympatric with and hybridise freely with

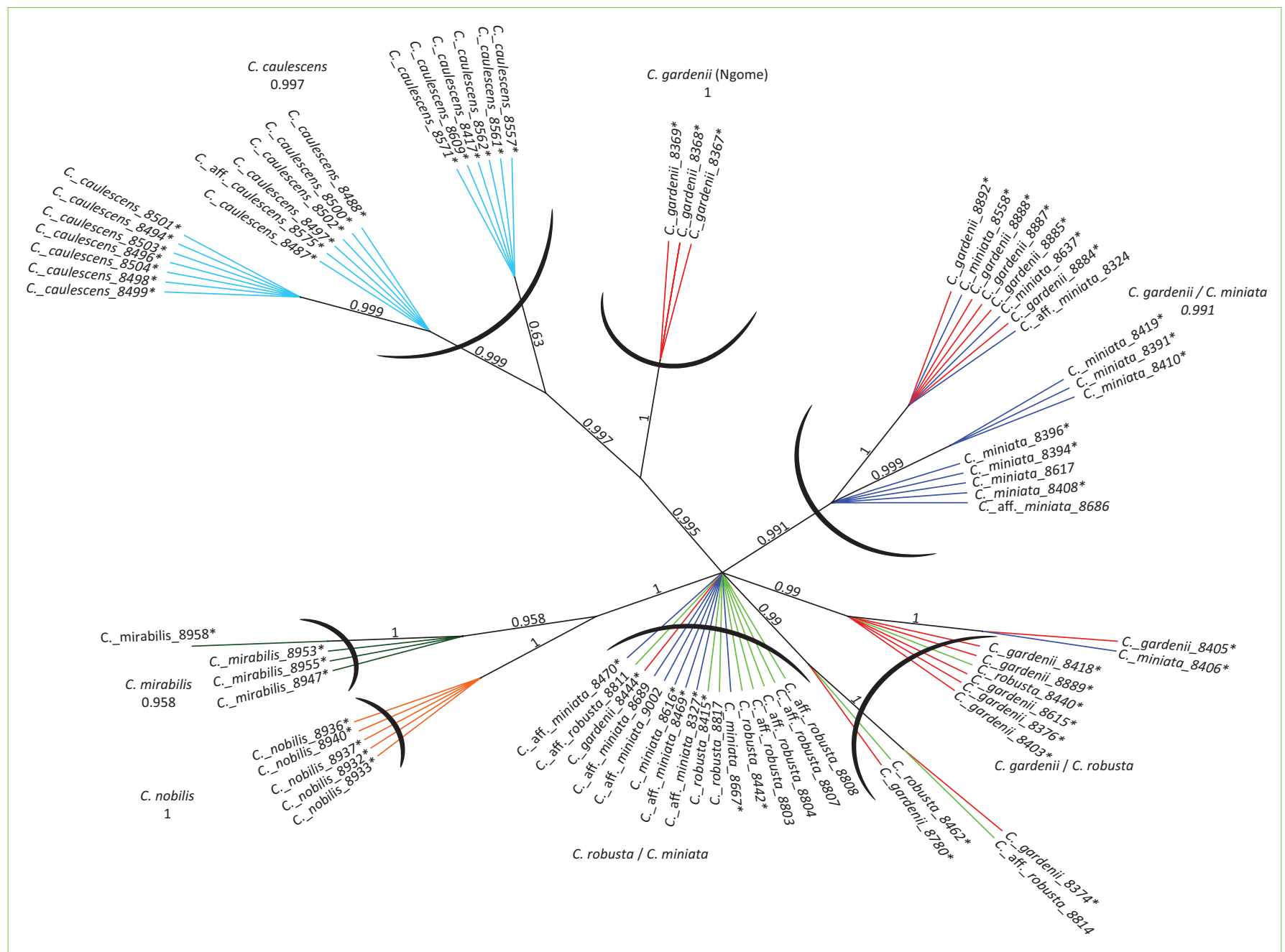

Source: Authors own work

FIGURE 2: Unrooted tree of the combined matK and rbcLa matrix. Each species is represented by different coloured branches: light blue, $C$. caulescens; dark blue, C. miniata; red, C. gardenii; light green, C. robusta; dark green, $C$. mirabilis; orange, $C$. nobilis. The thick black curved lines link similar species together based on their monophyletic groupings (such as C. robusta or C. miniata). The values on the branches are the posterior probabilities from the Bayesian analysis. 


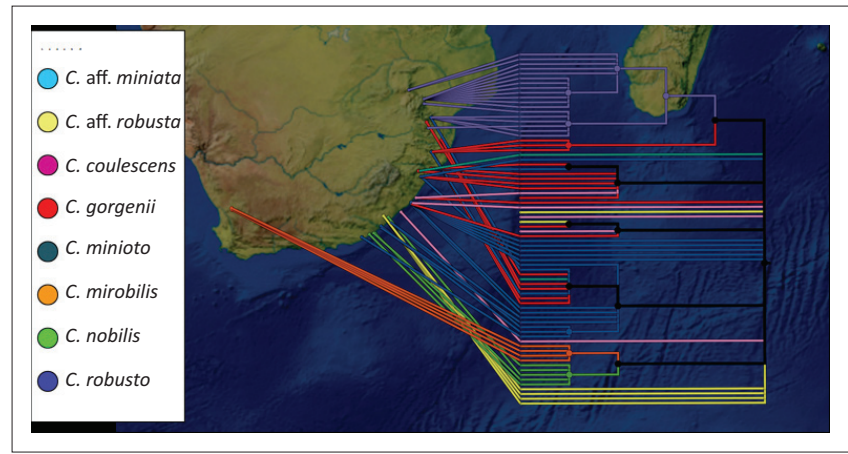

Source: Authors' own work

FIGURE 3: A phylogeographic comparison based on the Bayesian inference cladogram to indicate the low correlation between the phylogeny and geographic distribution in Clivia.

C. miniata resulting in the natural hybrid, C. ×nimbicola (Swanevelder et al. 2006). Clivia caulescens was divided into three haplotypes (Figure 1). The first haplotype is unique to Mariepskop Forest Reserve, but is not represented by all the plants from this population (three specimens from Mariepskop share their haplotype with the second haplogroup). The second haplogroup is widespread from the most northern (Wolkberg Mountains) to the most southern locality (Swaziland). The third haplogroup is mainly limited to the most southern distribution area (Bearded Man Mountains and Swaziland), but a single specimen from the central distribution area (God's Window) shares this haplotype. Clivia caulescens has three to five mutations corresponding to three haplogroups.

Phylogenetic results from the combined matK and rbcLa BI cladogram are presented in Figures 2 and 3. Three species (C. mirabilis, C. nobilis and C. caulescens) can be clearly identified based on monophyletic groupings in the BI analysis. The other species (C. miniata, C. gardenii, C. robusta and the affinis specimens) are paraphyletic. These results imply there is very little or no correlation between the phylogenetic cladogram and geographical distribution in Clivia (Figure 3).

Clivia miniata has a widespread distribution covering areas over three provinces and two countries, Eastern Cape, KwaZulu-Natal and Mpumalanga in South Africa and Swaziland. Clivia miniata has eight haplogroups, of which five are unique to the species. Clivia mirabilis is the only species in the western part of South Africa on the border between the Western and Northern Cape and has a unique haplogroup.

Clivia gardenii is a pendulous species from KwaZulu-Natal, of which the most southern distribution is Durban (Swanevelder \& Fisher 2009). Felbert (2003) indicates that the distribution is as far south as Port Edward near the border between KwaZulu-Natal and the Eastern Cape. Clivia gardenii has six different haplogroups, of which three are unique to C. gardenii. The other three remaining haplogroups are shared with C. aff. miniata, C. aff. robusta, C. miniata and C. robusta (haplogroup 1); C. robusta (haplogroup 2) and C. miniata (haplogroup 3).
Clivia robusta and $C$. nobilis are species with pendulous flowers from the Eastern Cape Province and are separated from an area of the species C. miniata known for its uprightstanding flowers. Clivia nobilis has a unique haplogroup, whereas $C$. robusta has two haplogroups that are not unique to the species.

A rare yellow flowering form has been observed in nature in all six Clivia species. Watson (1899) recognised this yellow form in C. miniata as a new variety (C. miniata var. citrina Watson) and since then new yellow varieties have been described for C. gardenii (C. gardenii var. citrina Swanevelder et al.) as well as C. robusta (C. robusta var. citrina Swanevelder et al.).

After the discovery and recognition of the yellow C. miniata var. citrina Watson, it was predicted in 1899 that more atypical colour variations (excluding the more common orange and yellow varieties observed in nurseries) will be found beyond the borders of KwaZulu-Natal (Watson 1899). Plants with unusual colour variants, such as 'versicolour' (contrasting inner and outer tepals), 'splash' (an unusual splash colouration), soft pink pastels, blushed yellows (plants that are more light sensitive) and ruby steward (deep yellow with pink flecking and spotting), have been collected and are preserved in a Heritage collection in KwaZulu-Natal (Chubb 2008). Examples of additional colour variants have been observed in numerous Clivia populations since the discovery of the first yellow plants including various pastel colours, such as peach and apricot. According to our results, the yellow colour variant does not deserve separate status and should be regarded as natural variation in the species.

\section{Network for the complex}

The largest haplogroup consists of 14 specimens representing the species groups, C. miniata (Spies 8667, 8616), C. aff. miniata (Spies 8327, 8469, 8689, 8470), C. gardenii (Spies 8444), C. robusta (Spies 8442, 8415) and C. aff. robusta (Spies 8808, 8807, 8804, $8803)$. These species have no significant structure or speciesspecific haplotype groupings.

\section{Relationships in Clivia}

Three species are molecularly distinct in the BI cladograms and network based on the combined matK and rbcLa data set. These are C. mirabilis, C. nobilis and C. caulescens. This finding supports previous findings of clear lineage formation involving these three species (Spies, Grobler \& Spies 2011). An unknown sample falling in the same monophyletic groups as any of these species in a BI cladogram has a posterior probability of 1.0 of belonging to C. mirabilis or C. nobilis and a posterior probability of 0.997 of belonging to $C$. caulescens.

Although C. caulescens has three haplotypes in the network, the number of steps (3-5) to the separation of these haplogroups into separate species is small and gives therefore 
weak support for the monophyly of these populations (haplogroups) as separate species. Furthermore, analyses relying on the intra- and interspecific genetic distances such as those performed by BOLD, ABGD and SpeciesIdentifier fail to recognise $C$. caulescens as monophyletic. This is mainly because of the degree of intraspecific variation (mean of 0.12 ).

Clivia mirabilis and C. nobilis are each geographically isolated with very little or no gene flow to other species. Clivia mirabilis grows in a few small isolated populations in the Northern and adjacent Western Cape provinces and has probably speciated because of isolation by distance. The geographic separation between C. mirabilis in the west and the other species in the east was primarily caused by climate change during the Cenozoic period leading to the extinction of tropical flora (Conrad, Reeves \& Rourke 2003; Linder, Meadows \& Cowling 1992; Meerow \& Clayton 2004; Swanevelder \& Fisher 2009). This is the only species in the Northern and Western Cape provinces; the geographic distance to the closest Clivia species (C. nobilis) is approximately $650 \mathrm{~km}$ east-southeast (ESE) (by direct measurement using Google Earth Pro). The isolation of C. mirabilis resulted in a lack of intraspecific variation. The nearest neighbours are C. robusta in matK and C. gardenii in rbcLa with genetic distances of 0.37 and 0.56 , respectively, separating these species from C. mirabilis (Table 4). Clivia gardenii has the largest degree of intraspecific variation with a mean distance of 0.36 (and maximum 0.7 ) in matK, followed by C. miniata (mean distance of 0.24 and maximum distance of 0.62 ). Clivia caulescens and C. robusta both have a mean intraspecific distance of 0.12 (maximum of 0.25 ) in matK. The intraspecific distances in $r b c L a$ are 0-0.19 (Table 4).

The geographic range of $C$. nobilis covers a $500 \mathrm{~km}$ stretch ranging from slightly north of Port Elizabeth to Coffee Bay in the Eastern Cape. Clivia nobilis is adapted to tolerate the salty, sandy and intense light conditions adjacent to the coastal areas of the Eastern Cape (Swanevelder \& Fisher 2009). There are a few rare localities where C. nobilis and C. miniata overlap; the gene flow in these areas results in mutating colonies, containing morphologically unusual plants (Haselau 2010). Various mechanisms may have contributed to speciation of C. nobilis, of which the most dominant may have been adaptation to the harsh environmental conditions near the coast. Clivia nobilis and C. mirabilis share the same nearest species (C. robusta in matK and C. gardenii in $r b c L a$ ).

Clivia caulescens, the species occurring furthest north in Limpopo and Mpumalanga provinces, may have diverged from other Clivia species because of isolation by altitude. This species has a geographic distribution centred on high-lying areas in the Barberton Greenstone Belt region (elevation of 600 m-1800 m) (McCarthy \& Rubidge 2006), Mariepskop Forest Reserve (elevation $\sim 1026 \mathrm{~m}$ ) and Wolkberg (elevation $\sim 846 \mathrm{~m}$ ). Clivia caulescens consists of three haplotype groups covering areas in Swaziland and in Mpumalanga. The first haplogroup correlates with populations in Swaziland (two specimens), and specimens in Mpumalanga at the God's Window tourist site (one specimen) and the Bearded Man Mountain (three specimens). Haplogroup 2 consists of three specimens from Mariepskop and two from the Wolkberg area. The last haplogroup consists only of specimens from Mariepskop.

Clivia miniata has the widest distribution of all Clivia species studied, occurring in patches from the most northerly point of the C. nobilis distribution area to the most southerly end of the C. caulescens range. Mutating colonies occur where C. miniata co-exists with other species (Haselau 2010). The first of these populations is located in the Songimvelo Nature Reserve on the Bearded Man Mountain in Mpumalanga. This is where the only described semi-pendulous hybrid, C. xnimbicola, exists as a result of crosses between C. miniata and $C$. caulescens. The Ngome forest contains large numbers of yellow-flowered C. gardenii plants and is where the type specimen for C. gardenii var. citrina was originally collected (Swanevelder et al. 2005). These plants have a unique round thickening at the base of the stem, which is not a typical morphological trait of C. gardenii. Based on a distribution map of Felbert (2003), another overlapping area between C. miniata and C. gardenii is a $4946 \mathrm{~km}^{2}$ area with a $630 \mathrm{~km}$ stretch from Port Edward to Eshowe and $73 \mathrm{~km}$ inland to Pietermaritzburg. The final overlapping distribution between these two species is a small area around Port St. Johns in the Eastern Cape (Felbert 2003).

Clivia miniata shares only a small fraction of a geographical area with $C$. nobilis, which is a $65 \mathrm{~km}$ stretch between two major rivers, the Great Kei River and the Mbashe River (measured in Google Earth Pro, according to the Clivia distribution map of Felbert [2003]).

A Clivia population in the area of the Mzamba River in the Eastern Cape grows in a dense and rocky habitat in a thicket biome. The leaves and flowers of these plants are unusual in that the leaves are greyish and hard and stems are present. The last is characteristic of $C$. caulescens in the most northern distribution range of Clivia. The flowers are upright, drooping or spider-like and have various colours such as pastel, orange or deep red (Forbes-Harding 2008). For the purpose of this article, these specimens are referred to as C. aff. miniata.

Clivia gardenii and C. robusta (previously known as swamp gardenii) are distinguished from each other by differences in their geographical range and morphology. Clivia gardenii grows in well-drained soil. The distribution is mainly in central and north-eastern parts of KwaZulu-Natal (north of Durban) (Swanevelder \& Fisher 2009), and as far south as Port Edward (Felbert 2003). The distribution of C. robusta is confined to a small area in the Pondoland centre of endemism from Port Edward as the northern border to the most southerly distribution around Lusikisiki (Dixon 2005). This species prefers swampy conditions. The C. robusta plants in the north of the distribution area resemble C. gardenii. In the 
southern distribution area, the plants have a greater resemblance to C. nobilis (Dixon 2005). The morphological differences between $C$. robusta and C. gardenii are that C. robusta is, as its name suggests, more robust with a prominent stem, it has more flowers (15-40) compared to the 14-20 of C. gardenii and the leaves differ slightly (Swanevelder \& Fisher 2009).

Ran, Murray and Hammett (2001b) divided C. miniata into five groups based on a randomly amplified polymorphic DNA (RAPD) analysis. The network analysis in this study divides C. miniata into eight haplogroups. Three of these groups are shared with other species. Clivia miniata shares the largest of these three haplogroups with $C$. gardenii, $C$. aff. robusta, C. robusta and C. aff. miniata.

There are few areas where C. gardenii and C. miniata do not overlap. For C. gardenii, this is in the vicinity of Vryheid, and for C. miniata, it is an $85 \mathrm{~km}$ stretch from the vicinity of the Mbashe River to Port St. Johns in the Eastern Cape where it has no geographical overlap with other species.

From the network (Figure 1) and the BI cladogram (Figure 3), there is no clear differentiation between the species in the Eastern Cape (excluding C. nobilis) and KwaZulu-Natal. The species $C$. miniata, C. gardenii, C. robusta and the $C$. aff. miniata and $C$. aff. robusta specimens included in this study hybridise readily in cultivation and in nature. The lack of isolating mechanisms, such as isolation by distance or by geographical features, contributes to incomplete lineage sorting.

This study supports the findings of Ran, Hammett and Murray (2001a) that C. miniata, C. gardenii and C. robusta are closely related and we suggest that these species (including the yellow variants) need taxonomic revision. We also suggest that the term $C$. gardenii complex be used as a collective term for C. gardenii, C. robusta, C. aff. robusta and C. aff. miniata. These species contain many morphologic and genetic variations, and it may be difficult to delimit its members based on morphology and molecular data. The key reasons for this taxonomic overlap between species may lie in their geographic distributions or close proximity of different species, leading to hybridisation (ancient or recent) or other factors like adaptation to habitat conditions, for example, swampy areas leading to stem formation.

\section{Conclusions}

This article is the first report of the use of matK and rbcLa DNA barcodes to support the motivation for a taxonomic revision of Clivia.

Clivia mirabilis and C. nobilis have DNA barcodes that clearly distinguish them from the rest of the species. The two-locus barcode of matK and rbcLa can be used to identify both of these species.

Clivia caulescens consists of three haplogroups. The phylogenetic support for the monophyletic grouping is strong. The low number of mutations (3-5) separating C. caulescens from the C. gardenii complex is an indication that this species is closely related to the complex.

The C. gardenii complex consists of the species in the Eastern Cape (excluding C. nobilis) and KwaZulu-Natal. Although these species are distributed over a large geographic area, ancient and current gene flow results in morphologic and genetic overlap amongst them. This causes confusion with the identification and classification of many specimens.

This study not only provides us with DNA barcodes for C. mirabilis, C. nobilis and C. caulescens but also proves that DNA barcodes have insufficient discriminatory power to distinguish between C. miniata, C. gardenii and C. robusta as they are currently circumscribed morphologically. The latter three species have incomplete lineage sorting, and a taxonomic revision of these species is suggested.

\section{Acknowledgements}

The authors thank the Canadian Centre for DNA Barcoding (CCDB, Guelph, Ontario, Canada) and Marli Watson (Mzamba specimens - University of the Free State) for sequencing some specimens, the Clivia Society for financial support, Mrs H. Bindeman for technical support and Prof. J.P. Grobler and Mrs L. van der Westhuizen for constructive comments on the manuscript.

\section{Competing interests}

The authors declare that they have no financial or personal relationships that may have inappropriately influenced them in writing this article.

\section{Authors' contributions}

P.S. was responsible for conducting the research and writing the thesis. J.J.S. was responsible for contributing some ideas to the study and writing this manuscript.

\section{References}

Bruni, I., Galimberti, A., Caridi, L., Scaccabarozzi, D., De Mattia, F., Casiraghi, M. et al., 2015, 'A DNA barcoding approach to identify plant species in multiflower honey', Food Chemistry 170, 308-315. https://doi.org/10.1016/j.foodchem.2014.08.060

CBOL Plant Working Group, 2009, 'A DNA barcode for land plants', Proceedings of the National Academy of Sciences of the United States of America 106, 12794-12797. https://doi.org/10.1073/pnas.0905845106

Chubb, S., 2008, 'Focus on heritage Clivia miniata with unusual colourations', Clivia 10, 41-44.

Conrad, F., Reeves, G. \& Rourke, J.P., 2003, 'Phylogenetic relationships of the recently discovered species: Clivia mirabilis', South African Journal of Botany 69, 204-206. https://doi.org/10.1016/\$0254-6299(15)30347-1

Dixon, R., 2005, 'Clivia robusta "maxima”', Clivia 7, 62.

Edgar, R.C., 2004, 'MUSCLE: Multiple sequence alignment with high accuracy and high throughput', Nucleic Acids Research 32, 1792-1797. https://doi.org/10.1093/nar/ gkh340

Felbert, C., 2003, 'Map of known distribution of Clivia species', Clivia 5, 96-97.

Forbes-Harding, A., 2008, 'Mzamba grey Clivia miniata', Clivia News 17, 10-11.

Ford, C.S., Ayres, K.L., Toomey, N., Haider, N., Van Alphen Stahl, J., Kelly, L.J. et al., 2009, 'Selection of candidate coding DNA barcoding regions for use on land plants', Botanical Journal of the Linnean Society 159, 1-11. https://doi. org/10.1111/j.1095-8339.2008.00938.x

Haselau, W., 2010, 'Clivia nobilis', Clivia 12, 13. 
Hollingsworth, P.M., Forrest, L.L., Spouge, J.L., Hajibabaei, M., Ratnasingham, S., Van der Bank, M. et al., 2009, 'A DNA barcode for land plants', Proceedings of the
National Academy of Sciences 106, 12794-12797. https://doi.org/10.1073/ pational Academy

Hollingsworth, P.M., Graham, S.W. \& Little, D.P., 2011, 'Choosing and using a plant DNA barcode', PLoS One 6(5), e19254. https://doi.org/10.1371/journal. pone.0019254

Kearse, M., Moir, R., Wilson, A., Stones-Havas, S., Cheung, M., Sturrock, S. et al., 2012 'Geneious basic: An integrated and extendable desktop software platform for the organization and analysis of sequence data', Bioinformatics 28(12), 1647-1649. https://doi.org/10.1093/bioinformatics/bts199

Kress, W.J. \& Erickson, D.L., 2007, 'A two-locus global DNA barcode for land plants: The coding rbcL gene complements the non-coding trnH-psbA spacer region', PLoS One 2, e508. https://doi.org/10.1371/journal.pone.0000508

Lahaye, R., Van der Bank, M., Bogarin, D., Warner, J., Pupulin, F., Gigot, G. et al., 2008 'DNA barcoding the floras of biodiversity hotspots', Proceedings of the National Academy of Sciences 105, 2923-2928. https://doi.org/10.1073/pnas.0709936105

Levin, R.A., Wagner, W.L., Hoch, P.C., Nepokroeff, M., Pires, J.C., Zimmer, E.A. et al., 2003 'Family-level relationships of Onagraceae based on chloroplast $r b c L$ and $n d h F$ data', American Journal of Botany 90, 107-115. https://doi.org/10.3732/ajb.90.1.107

Linder, H.P., Meadows, M.E. \& Cowling, R.M., 1992, 'History of the Cape Flora', in R.M. Cowling (ed.), The ecology of Fynbos: Nutrients, fire and diversity, Oxford University Press, Cape Town, South Africa, pp. 536-541.

McCarthy, T. \& Rubidge, B., 2006, The story of earth \& life: A Southern African perspective on a 4.6-billion-year journey, Struik Publishers, Cape Town, South Africa, pp. 242-273.

Meerow, A.W. \& Clayton, J.R., 2004, 'Generic relationships among the baccate-fruited Amaryllidaceae (tribe Haemantheae) inferred from plastid and nuclear noncoding DNA sequences', Plant Systematics and Evolution 244, 141-155. https:// doi.org/10.1007/s00606-003-0085-2

Meier, R., Shiyang, K., Vaidya, G. \& Ng, P.K.L., 2006, 'DNA barcoding and taxonomy in Diptera: A tale of high intraspecific variability and low identification success', Systematic Biology 55, 715-728. https://doi.org/10.1080/10635150600969864
Puillandre, N., Lambert, A., Brouillet, S. \& Achaz, G., 2011, 'ABGD, Automatic Barcode Gap Discovery for primary species delimitation', Molecular Ecology 21(8), 1864-1877. https://doi.org/10.1111/j.1365-294X.2011.05239.x

Ran, Y., Hammett, K.R.W. \& Murray, B.G., 2001a, 'Phylogenetic analysis and karyotype evolution in the genus Clivia (Amaryllidaceae)', Annals of Botany 87, 823-830. https://doi.org/10.1006/anbo.2001.1422

Ran, Y., Murray, B., \& Hammett, K.R., 2001b, 'Evaluating genetic relationships between and within Clivia species using RAPDs', Scientia Horticulturae 90, 167-179. https://doi.org/10.1016/S0304-4238(01)00253-9

Rastegar-Pouyani, E., Oraie, H., Khosravani, A., Kaboli, M., Mobaraki, A., Yousefi, M. et al., 2014, 'A re-evaluation of taxonomic status of Montivipera (Squamata: Viperidae) from Iran using a DNA barcoding approach', Biochemical Systematics and Ecology 57, 350-356. https://doi.org/10.1016/j.bse.2014.09.017

Ratnasingham, S. \& Hebert, P.D., 2007, 'BOLD: The Barcode of Life Data System (http://www. barcodinglife. org)', Molecular Ecology Notes 7, 355-364. https:// doi.org/10.1111/j.1471-8286.2007.01678.x

Rogstad, S.H., 1992, 'Saturated NaCl-CTAB solution as a means of field preservation of leaves for DNA analyses', Taxon 41, 701-708. https://doi.org/10.2307/ 1222395

Spies, P., Grobler, J.P. \& Spies, J.J., 2011, 'A review of phylogenetic relationships in the genus Clivia', Philosophical Transactions in Genetics 1, 168-207.

Swanevelder, D. \& Fisher, R.C., 2009, Clivia: Nature and nurture, Briza, Pretoria, South Africa.

Swanevelder, Z.H., Forbes-Hardinge, A., Truter, J.T. \& Van Wyk, A.E., 2006, 'A new variety of Clivia robusta', Bothalia 36, 66-67.

Swanevelder, Z.H., Van Wyk, A.E. \& Truter, J.T., 2005, 'A new variety of the genus Clivia', Bothalia 35, 67-68. https://doi.org/10.4102/abc.v36i1.337

Vaidya, G., Lohman, D.J. \& Meier, R., 2011, 'Sequence matrix: Concatenation software for the fast assembly of multi-gene datasets with character set and codon information', Cladistics 27, 171-180. https://doi.org/10.1111/j.1096-0031.2010. 00329.x

Watson, W., 1899, 'Clivia miniata var. citrina', The Garden 56, 338-339, t. 1246. 